\title{
A novel method for fabrication of Fe catalyst used for the synthesis of carbon nanotubes
}

\author{
E Z KARIMI ${ }^{\mathrm{a}, *}$, J VAHDATI-KHAKI ${ }^{\mathrm{a}}$, S M ZEBARJAD ${ }^{\mathrm{a}}$, I A BATAEV ${ }^{\mathrm{b}}$ and A G BANNOV \\ ${ }^{a}$ Department of Materials and Metallurgical Engineering, Faculty of Engineering, Ferdowsi University of Mashhad, \\ Mashhad, Iran \\ ${ }^{b}$ Department of Mechanical Engineering, Novosibirsk State Technical University, Pr. K. Marksa 20, 630092 \\ Novosibirsk, Russia \\ ${ }^{\mathrm{c}}$ Department of Chemical Engineering, Novosibirsk State Technical University, Pr. K. Marksa 20, 630092 \\ Novosibirsk, Russia
}

MS received 15 April 2013; revised 6 June 2013

\begin{abstract}
Carbon nanotubes (CNTs) have been grown by decomposition of propane over a nanocamposite catalyst by chemical vapour deposition (CVD). The catalyst was prepared from an aluminum/iron oxide/graphite mixture milled in a high-energy ball-milling equipment. Scanning and transmission electron microscopies, Raman spectroscopy and $X$-ray diffraction measurements have been carried out in order to investigate the catalyst and synthesized CNTs. The results show that iron nanoparticles are produced in an alumina and ball-milled graphite matrix. This produced nanocomposite is used as a catalyst to synthesize CNTs via CVD successfully. The yield of CNTs formation was greatly influenced by the milling time and deposition temperature.
\end{abstract}

Keywords. Iron catalyst; mechanochemical; chemical vapour deposition; carbon nanotubes.

\section{Introduction}

Single-wall and multi-wall carbon nanotubes (CNTs) are currently the subject of an intense research effort owing to the outstanding properties that they may possess. Many methods have been used to produce CNTs, but they mainly fall into the main categories such as arc discharge in the absence or presence of metal (Journet et al 1997), laser vapourization of a metal-graphite composite target (Thess et al 1996), carbon monoxide disproportionation on a metal catalyst and hydrocarbon pyrolysis (Dai 2002; Magrez et al 2010), using a metal nanocatalyst (Laurent et al 1998). Indeed, in many mentioned synthesis methods, fabrication of CNTs need nanometric metal particles (Laurent et al 1998). Transition metals (Fe, Co, Ni, etc) are used as catalysts, which provide both nucleation and growth sites for CNTs (Yunyu et al 2007; Paul and Samdarshi 2011). It has been found that the catalyst plays an important role in the rate of growth, purity and structural properties of the resulting nanotubes (Alexiadisa and Verykiosa 2009). In this case, Rümmeli et al (2007), for example, showed that both the diameter and number of walls of the resultant CNTs increase proportionally to the size of the catalyst particle. Also, Jianwei et al (2005), through using the layer-by-layer assembly

\footnotetext{
*Author for correspondence (ebrahimzk88@gmail.com)
}

method, fabricated catalyst particles of a controlled size distribution for CNT growth and showed a reasonably graphitized structure with an outer diameter of $15 \mathrm{~nm}$. Formation of non-selective forms of carbon was also observed by Perez-Cabero et al (2003) with the iron-silica catalysts with higher iron content. They explained this result by the fact that the degree to which metallic iron aggregates upon reduction into metallic particles depends on the iron content. Thus, catalysts with higher iron content exhibit larger metallic iron particles, leading to other forms of carbon than nanotubes.

It is worth noting that the catalyst particle size is an important factor in CNT growth and catalysts with large particle sizes have been claimed to be ineffective (Nerushev et al 2003; Ajayan 2004). The increase of mean crystallite size led to a decrease of the surface area. Lower surface area, more effective encapsulation with carbon, resulted in a decrease of number of free active sites for hydrocarbon decomposition (Narkiewicz et al 2010). The graphene shell at the surface of the particle immediately deactivates their catalytic role by inhibiting incorporation of the carbon species from the carbonaceous gas and stops nucleation and growth from the particle (Parka et al 2002). A crucial point is to control the synthesis of metal particles with desired sizes that are stable at the high temperatures required for the CNT formation ( $\mathrm{Yu}$ et al 2005). Various processing routes have been developed for the synthesis and commercial 
production of nanocatalysts. The most usual methods to prepare nanocatalysts are mechanical milling (Muñoz et al 2007), impregnation (Takenaka et al 2003), co-precipitation (Narkiewicz et al 2007) and sol-gel (Luisetto et al 2008). Among these methods, mechanochemical synthesis, that is, chemical reactions induced by high-energy ball milling (HEBM), is a well-known method for fabrication of novel materials such as nanocomposites. Highenergy ball milling can enhance the kinetics of reactions of components and results to induce chemical reactions in powder mixtures at lower temperatures or even at room temperature. This technique can lead to the formation of interpenetrating phase composites with nanosized microstructures. One of the most important specifications of such phases is better performance rather than that of conventional microcrystalline counterparts (Suryanarayana 2001). In fact, in mechanochemical approach, the nanostructured crystalline will be produced by the structural decomposition of coarser-grained structures as the result of severe plastic deformation during HEBM. This has become a popular method to make nanocrystalline materials because of its simplicity, the relative inexpensive equipment and the applicability to essentially all classes of materials. In the past decades, mechanochemical approach has been successfully applied to the synthesis of ultrafine metals (Ding et al 1995).

Based on a literature survey done by the authors, using mechanochemical process for fabrication of catalysts needed for CNTs growth has not received much attention. For example, Ding et al (2004) used this method to make $\mathrm{Al}_{2} \mathrm{O}_{3} / \mathrm{Fe}(\mathrm{Co}$, Ni) nanocomposites for MWCNTs and SWCNTs growth. Liu et al (2006) synthesized $\mathrm{MgO} / \mathrm{Fe}$ nanocomposite using ball milling. For this purpose, they mixed $\mathrm{Mg}$ and $\mathrm{Fe}_{2} \mathrm{O}_{3}$ along with $\mathrm{Mg}$ powder for $24 \mathrm{~h}$. Using ball milling for production of metal oxide is very common. For example, Xiaomei et al (2003) produced aluminum hydroxide and iron oxide powders after $24 \mathrm{~h}$ milling to obtain nanocrystals of size $\sim 20 \mathrm{~nm}$. They used the material as a catalyst for preparing CNTs. Perhaps the most important limitation of the methods proposed by previous researchers is attributed to two or three steps of their processes. We believe that by our new method, nanocomposite catalyst can be produced in just one step, besides decreasing the milling time up to $15 \mathrm{~min}$.

\section{Methods}

\subsection{Materials}

Commercially pure $\mathrm{Al}$ (purity more than $99 \%,<100 \mu \mathrm{m}$ ), $\mathrm{Fe}_{2} \mathrm{O}_{3}$ (purity more than $99 \%,<100 \mu \mathrm{m}$ ) and graphite (purity of $99.9 \%,<200 \mu \mathrm{m}$ ) powders, all from SigmaAldrich Co., were used as raw materials in this study. SEM micrographs of the starting powders are shown in figure 1 .

\subsection{Catalyst synthesis}

Several mixtures of iron oxide and aluminum powders along with $10 \mathrm{wt} \%$ of graphite powder were mechanically milled for different times. Experiments were conducted in a centrifugal planetary mill AGO-2S with two $150 \mathrm{~mL}$ steel barrels filled with $10 \mathrm{~mm}$ zirconium oxide balls. A $2 \mathrm{~g}$ sample of $\mathrm{Al}-\mathrm{Fe}_{2} \mathrm{O}_{3}-10 \mathrm{wt} \%$ graphite mixture and $150 \mathrm{~g}$ balls was put in barrels. The molar ratio of Al to $\mathrm{Fe}_{2} \mathrm{O}_{3}$ was kept constant at $2: 1$, according to stoichiometry of thermite reaction (1):

$$
2 \mathrm{Al}+\mathrm{Fe}_{2} \mathrm{O}_{3}=2 \mathrm{Fe}+\mathrm{Al}_{2} \mathrm{O}_{3} .
$$

Ball milling was carried out at a rotation speed of $1000 \mathrm{rpm}$ under air atmosphere and the milling time was varied from 2.5 to $15 \mathrm{~min}$. The vials were cooled by circulating water around them.

The adiabatic temperature and the heat released from exothermic reaction during milling can be controlled by varying the percentage of graphite (table 1). This is because the formation of $\mathrm{Fe}$ and $\mathrm{Al}_{2} \mathrm{O}_{3}$ from the reactants is a severely exothermic reaction. Here, only $10 \mathrm{wt} \%$ of graphite was selected.

\subsection{CNTs synthesis}

The synthesis of CNTs was carried out by a CVD method using nanocomposite powders obtained by ball milling $\left(\mathrm{Fe} / \mathrm{Al}_{2} \mathrm{O}_{3} / \mathrm{C}\right)$ mentioned in detail before and the so-called catalyst. As much as $0 \cdot 15 \mathrm{~g}$ of catalyst was spread over a ceramic boat and placed in a tubular reactor. Propane $\left(\mathrm{C}_{3} \mathrm{H}_{8}\right)$ was used as the carbon source and carbonization was performed at a temperature range of $625-850{ }^{\circ} \mathrm{C}$ in $\mathrm{Ar}-\mathrm{C}_{3} \mathrm{H}_{8}$ mixture for $30 \mathrm{~min}$. Propane was introduced into the gas stream at a flow rate of $30 \mathrm{~mL} / \mathrm{min}$ diluted with $200 \mathrm{~mL} / \mathrm{min}$ argon carrier. After reaction, the system was cooled down to room temperature and the products were characterized by transmission electron microscopy (TEM) and scanning electron microscopy (SEM) and thermogravimetric analysis (TGA). The effect of growth temperature on the formation yield of CNTs was also examined by carrying out the propane decomposition reaction at different temperatures, i.e. 625, 700 and $850{ }^{\circ} \mathrm{C}$. The synthesized CNTs were cooled in Ar flow and the weight of the deposited CNTs was measured.

Table 1. Weight percent of graphite in mixture and related adiabatic temperatures.

\begin{tabular}{lc}
\hline Graphite $(w t \%)$ & $\begin{array}{c}\text { Adiabatic } \\
\text { temperature }(\mathrm{K})\end{array}$ \\
\hline 5 & 3130 \\
10 & 2922 \\
15 & 2741 \\
\hline
\end{tabular}



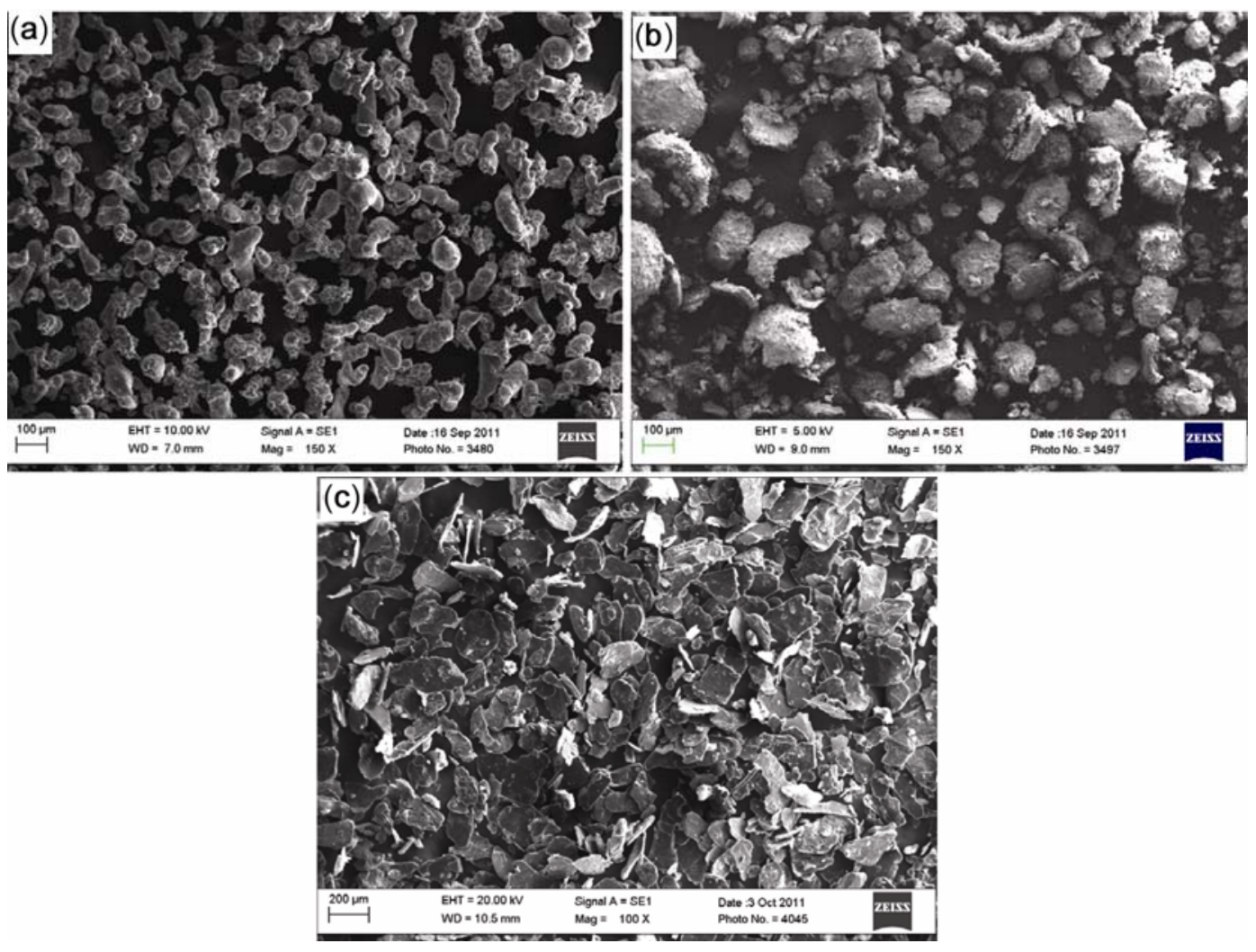

Figure 1. SEM images of initial materials: $\mathrm{Al}(\mathbf{a}), \mathrm{Fe}_{2} \mathrm{O}_{3}$ (b) and graphite (c).

The yield of deposited carbon was calculated from the following equation:

$$
\text { Yield }=\left(\left(W_{2}-W_{1}\right) / W_{1}\right) 100 \%
$$

where $W_{1}$ is the initial weight of the catalyst (milled products) and $W_{2}$ the weight of carbon deposited and catalyst.

\subsection{Instrumental techniques}

SEM observations were performed using a Zeiss EVO $50 X V P$ at an accelerating voltage of $15 \mathrm{kV}$. For SEM analysis, a thin layer of powder was spread over the conductive adhesive tape. For better conductivity, a thin layer of gold $(\sim 10 \mathrm{~nm})$ was deposited on the surface. The TEM analyses were carried out with a Tecnai 20 G2 model of FEI at an operating voltage of $200 \mathrm{kV}$. The obtained samples were dispersed ultrasonically in ethanol. A drop of the dispersed suspension was placed on a microgrid coated with thin layer of amorphous carbon and dried in air before fitting into the TEM apparatus. X-ray diffraction analysis performed by an ARL X'TRA advanced apparatus, using $\mathrm{CuK} \alpha$ radiation. TGA was performed using a NETZSCH STA $449 \mathrm{C}$ at a heating rate of $10{ }^{\circ} \mathrm{C} / \mathrm{min}$ to warm the samples from room temperature up to $900{ }^{\circ} \mathrm{C}$ in a mixture of $\operatorname{argon}(20 \mathrm{~mL} / \mathrm{min})$ and oxygen $(10 \mathrm{~mL} / \mathrm{min})$ atmosphere. A Raman spectrometer (T64000 Horiba Jobin Yvon) was also used to identify the crystallinity of CNTs. The 514-nm line of an Ar-Kr laser was used for excitation. For purification, $1 \mathrm{~g}$ of synthesized CNTs was refluxed in $150 \mathrm{~mL}$ of concentrated nitric acid for $4 \mathrm{~h}$. After refluxing, the mixture was cooled to room temperature, diluted with distilled water, and filtered through a $1.2 \mu \mathrm{m}$ pore-sized membrane. The product on the membrane was washed thoroughly with distilled water and dried at oven (at $80^{\circ} \mathrm{C}$ ) overnight.

\section{Results and discussion}

\subsection{XRD analysis}

Figure 2 shows the XRD patterns of milled powder mixture containing $\mathrm{Al}-\mathrm{Fe}_{2} \mathrm{O}_{3}-10 \%$ graphite after different milling times. The XRD pattern of powder mixture up to 2.5 min of milling time was identified as a mixture of iron oxide $\left(\mathrm{Fe}_{2} \mathrm{O}_{3}\right)$ and aluminum. It means that this time is not enough for having a mechanical induced reaction and ball milling up to $2.5 \mathrm{~min}$ had no effect on as-received powder mixture except for the broadening of Bragg peaks, which is caused by reduction of the crystallite size as well as microstrain appeared in the powder particles (Fecht 1995). Perhaps the main reason for lack of reaction can be attributed to the kinetic. Indeed, decreasing particle 


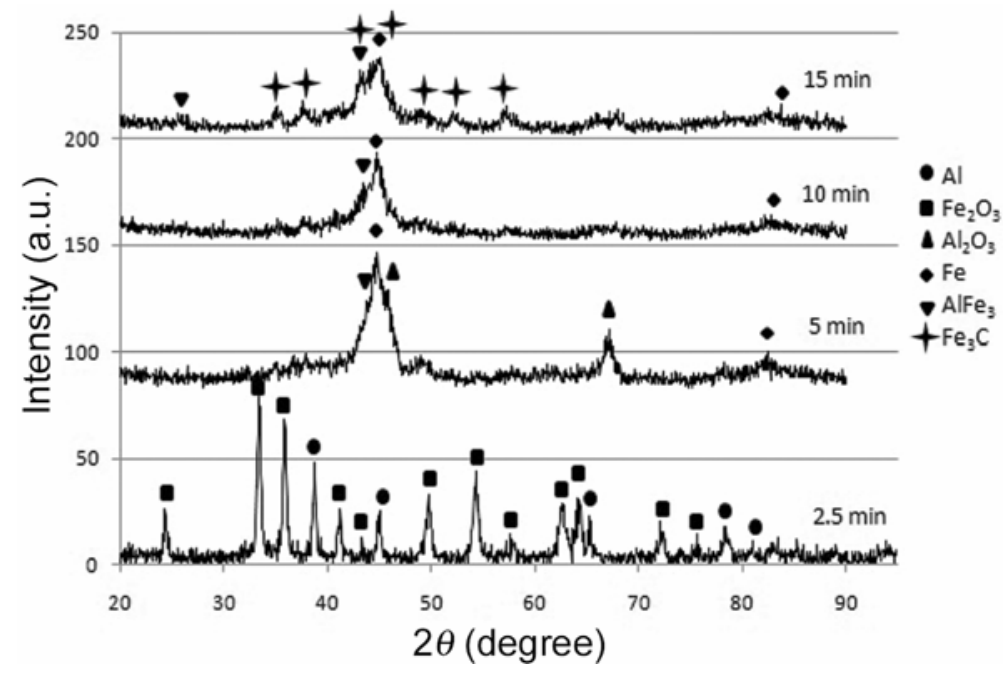

Figure 2. XRD patterns of mechanically-alloyed $\mathrm{Al}-\mathrm{Fe}_{2} \mathrm{O}_{3}-10 \%$ graphite powders after different times.

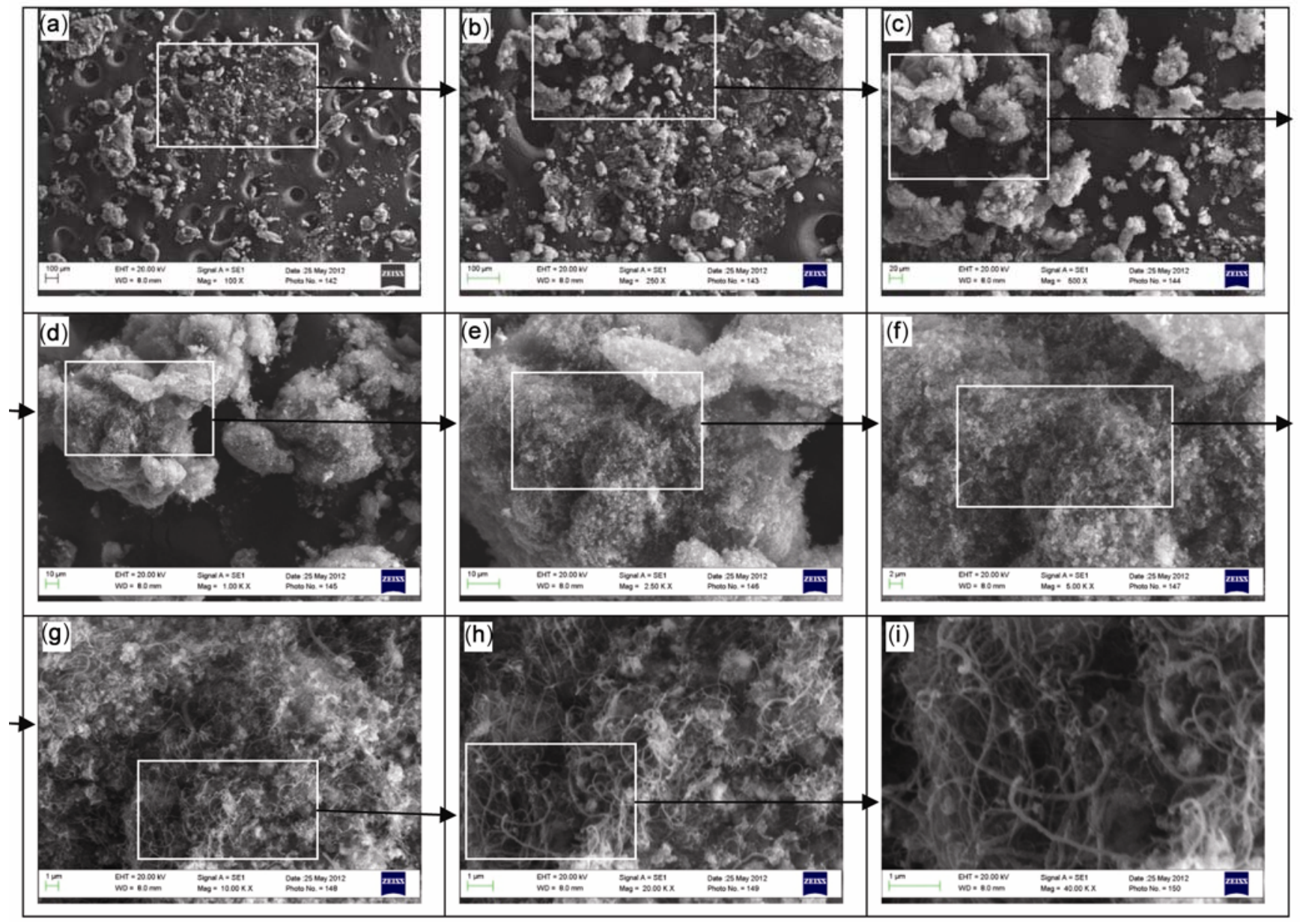

Figure 3. Scanning electron microscopy images in different magnifications showing the weblike net of carbon nanotube bundles covering the $\mathrm{Fe}-\mathrm{Al}_{2} \mathrm{O}_{3}-\mathrm{C}$ grains.

size due to increasing milling time make a new condition for kinetic reactions. As a matter of fact, reducing the crystallite size to nanometer range and increasing the defect densities can promote the reaction kinetically by providing short-circuit diffusion paths (Sheng et al 2002). Thus, one may conclude that increasing milling time for more than 2.5 min will cause to make a new phase such as $\mathrm{Al}_{2} \mathrm{O}_{3}$. Appearing of $\mathrm{Al}_{2} \mathrm{O}_{3}$ due to milling up to $5 \mathrm{~min}$ 


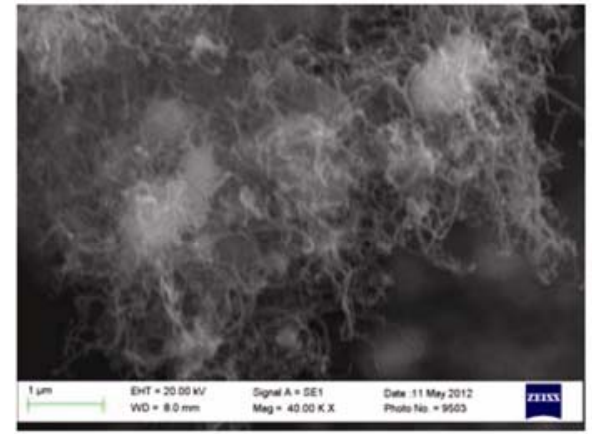

$625^{\circ} \mathrm{C}$

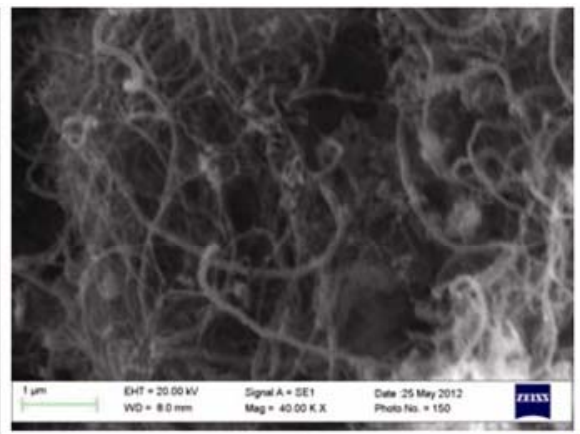

$700^{\circ} \mathrm{C}$

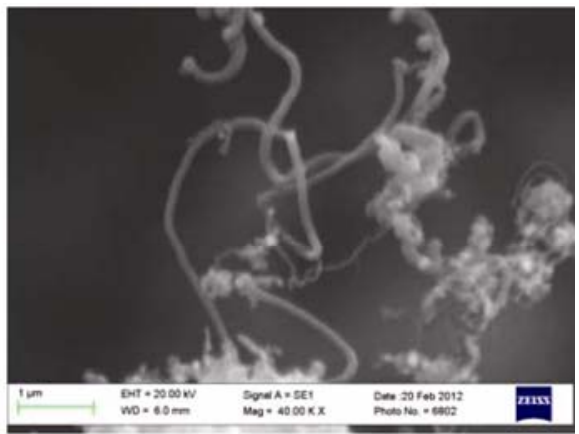

$850^{\circ} \mathrm{C}$

Figure 4. SEM micrographs of CNTs synthesized at different temperatures.

is shown in figure 2, implying that the oxidation/ reduction reaction has been induced by mechanochemical route. Consequently, during ball milling of $\mathrm{Fe}_{2} \mathrm{O}_{3}$ and $\mathrm{Al}$, reaction (1) takes place and can be further promoted by the dynamically maintained high reaction interface areas, as well as the short-circuit diffusion path provided by the large number of defects such as dislocations and grain boundaries induced during ball milling (Sharifi et al 2009). The intensities of the peaks corresponding to alumina crystals decrease remarkably and have been disappeared as milling time increased up to $10 \mathrm{~min}$. The formation of nanocrystalline materials during mechanical milling of ceramics or metallic powders is attributed to the intense cold working on the ball-milled powders. This leads to a dramatic increase in the number of imperfections (e.g., point and lattice defects), which leads to decrease in the thermodynamic stability of the starting materials (amorphization) (Eskandarany 2001). Therefore, the alumina peak could not appear in the spectrum and it means that it becomes amorphous or even nanocrystalline. With increasing milling time, the other interstitial compound $\left(\mathrm{Fe}_{3} \mathrm{C}\right)$ appeared as well as $\mathrm{AlFe}_{3}$ compound, while the intensity of iron peaks decreased slightly. This shows that continuing milling time may lead to formation of different intermetallic compounds. The lack of carbon peaks on XRD patterns is related to the lower intensity of carbon peaks compared with other materials.

\subsection{SEM observation}

Figure 3 shows the SEM images of a typical sample of carbon nanotubes with different lengths grown on mechanochemical products. The produced carbon nanotubes appear as spaghetti with disorder and random shape. Fabrication of CNTs due to mechanochemical method proves that the milled products $(\mathrm{Fe})$ play as catalysts. This is because CNTs need a catalyst for nucleating and growing particularly in CVD method. Also, it is obvious that the large quantity of carbon nanotubes were achieved by

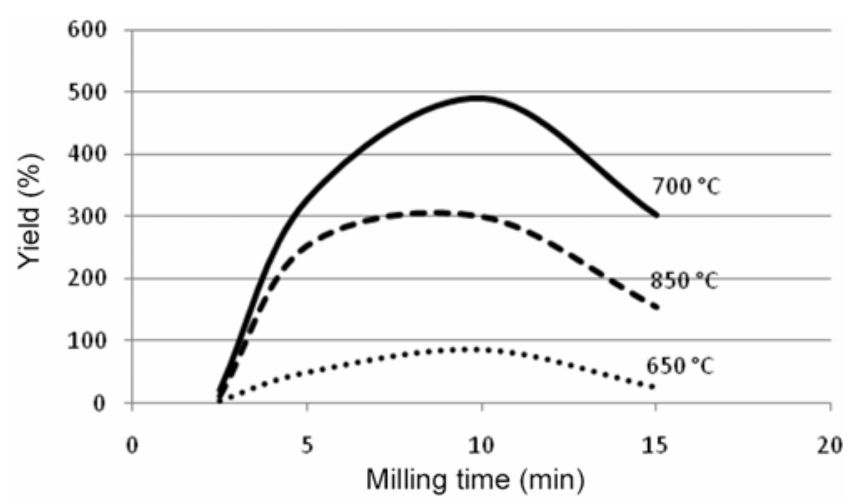

Figure 5. Yield of CNTs for samples milled at different times.

using this approach. As seen in the micrographs, each CNT nucleated and grew from a catalyst and since the quantity of $\mathrm{Fe}$ is much higher, the yield of CNTs formation can be high as well. So, this demonstrates that the mechanochemical method is a promising technique for the production of CNTs growth catalysts. In figure 4, it can be seen that the diameter of CNTs increases with increase in the annealing temperature.

The yield of CNTs is shown in figure 5. As it can be seen that the carbon yield increased with increase in milling time up to $10 \mathrm{~min}$. The yield of CNTs formation at annealing temperature of $625^{\circ} \mathrm{C}$ is low because of negligible decomposition of propane. The maximum value $(490 \%)$ is related to a sample that milled for $10 \mathrm{~min}$ and annealed at $700{ }^{\circ} \mathrm{C}$ for $30 \mathrm{~min}$. At longer milling times, the carbon yield decreased due to the decrease in catalytic activity. This seems to be related to producing cementite $\left(\mathrm{Fe}_{3} \mathrm{C}\right)$, which consumes some amount of iron catalyst. For higher growth temperatures, the average size of the active catalytic particles increases due to coalescence. The yield of CNTs initially increases with the annealing temperature (from 625 to $700{ }^{\circ} \mathrm{C}$ ) and then decreases at higher temperature $\left(850^{\circ} \mathrm{C}\right)$. By looking into more details on figure 5 , it can be concluded that $700^{\circ} \mathrm{C}$ is an optimum temperature for achieving the highest yield. This trend is similar to that found by Cui et al (2000) and Ducati 


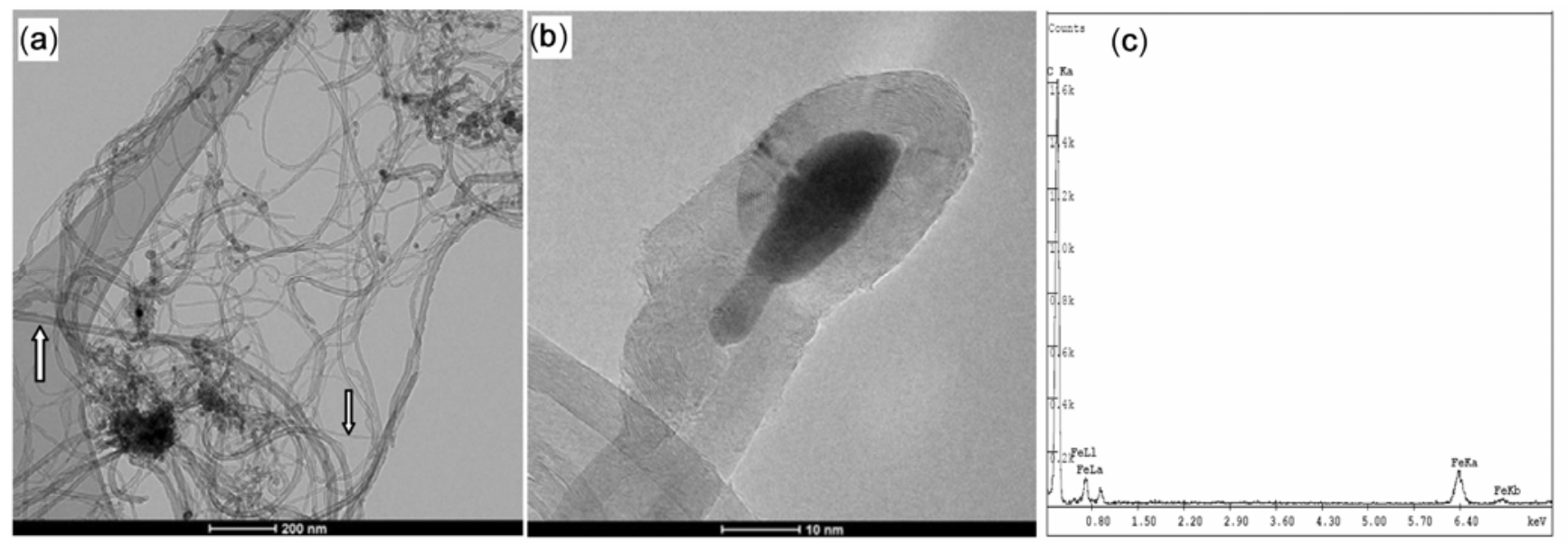

Figure 6. TEM micrographs showing the (a) as-grown CNTs synthesized by $\mathrm{CVD}$ at $700{ }^{\circ} \mathrm{C}$ over $\mathrm{Fe} / \mathrm{Al}_{2} \mathrm{O}_{3} / \mathrm{C}$ catalyst and $(\mathbf{b}, \mathbf{c})$ nanoparticle at the tip of CNT and related analysis.

et al (2002). Perhaps the main reason of this variation is related to both hydrocarbon decomposition rate and grain-size growth as temperature increases. Indeed, the lower yield of CNTs at low temperature (lower than $700{ }^{\circ} \mathrm{C}$ ) is due to the activation barrier for the surfacebulk penetration of carbon atoms at the catalyst particles (Juang et al 2004; Zhang et al 2008). The worse condition is whenever the temperature is higher than $700^{\circ} \mathrm{C}$. In this case, decreasing the yield of CNTs formation is referred to hydrocarbon decomposition rate. It leads to increase in the carbon supply rate, which results in exceeding the carbon diffusion rate. On the other hand, at high reaction temperatures, the decomposition rate of hydrocarbons is faster than the diffusion rate of carbon atoms, and, therefore, the catalyst can be encapsulated by excess carbon atoms and can deactivate. Finally, the carbon produced due to decomposition will accumulate on the catalysts and prevent their role in CNTs formation. In summary, the yield of CNTs depends on both hydrocarbon decomposition rate and carbon diffusion rate. At high temperature $\left(>700^{\circ} \mathrm{C}\right)$, the dominant mechanism is decomposition rate, while at lower temperature $\left(<700{ }^{\circ} \mathrm{C}\right)$, the rate of diffusion is much higher than that of decomposition rate (Juang et al 2004).

\subsection{TEM analysis}

Figure 6 displays TEM micrographs of the as-grown CNT sample, which has been fabricated over $\mathrm{Fe} / \mathrm{Al}_{2} \mathrm{O}_{3} / \mathrm{C}$ catalyst. From figure 6 , it is evident that many CNTs are entangled with each other. As is shown with arrows (figure 6(a)), there are carbon nanotubes with different diameters ranging between 10 and $50 \mathrm{~nm}$. Based on the TEM-EDX data, almost all the metal tips of the nanotubes formed on the particles were iron $(\mathrm{Fe})$. Figure $6(\mathrm{~b}$ and $\mathrm{c})$ demonstrate an iron nanoparticle at the tip of CNT. Therefore, it can be speculated that the growth mechanism of carbon nanotubes is tip growth (Dupuis 2005). Indeed, in the tip growth model, the metal catalyst particle might remove from the surface and move at the top of the growing carbon nanotube. The interaction between the catalyst particle and support is stronger at base-growth mechanism than tip-growth mechanism. So catalyst particle remains attached to the support (Dupuis 2005).

\subsection{Raman spectroscopy}

Raman spectroscopy probes the lattice vibrations of ordered carbon materials and is, therefore, extremely sensitive to the graphitic character of these structures. Thus, Raman spectroscopy is widely employed for the characterization of carbon samples, and in particular for carbon nanomaterials like nanofibers and nanotubes (Tessonnier et al 2009). The Raman spectra of CNT synthesized from 5 and 15 min milled powders are illustrated in figure 7(a and b), respectively. The centered peak at $\sim 1330 \mathrm{~cm}^{-1}$ is related to the band $\mathrm{D}$, caused by the defects in the structure of the $s p^{2}$ carbon and can be due to the lattice defects in the graphite sheet that make up CNTs. Also, this band indicates deposition of amorphous carbon, or nanotubes with large diameters, or even nanofibers, which have more defects than nanotubes (Bonadiman et al 2006). The peak at around $1580 \mathrm{~cm}^{-1}$ is related to the band $\mathrm{G}$, which is generated by the tangential modes of vibration of carbon $s p^{2}$. Actually, it is intensified by the presence of nanotubes of small diameter, which have few defects, and demonstrates the presence of crystalline graphitic carbon (Bonadiman et al 2006). The ratio between the heights of the peaks $\mathrm{D} / \mathrm{G}$ is 0.578 for $5 \mathrm{~min}$ and 0.676 for $15 \mathrm{~min}$ milled powders. It indicates that the degree of long-range ordered crystalline perfection of the CNTs grown using 5 -min milled powder is higher than that of CNTs grown using 15-min milled powders. The lower frequencies, between 100 and $250 \mathrm{~cm}^{-1}$, are denominated radial 
breathing mode (RBM). Peaks in this band are detected only when SWCNT and DWCNT are present (Maschmann et al 2006). In our case, it seems that there are some amounts of these types of carbon, but because of low quantity we could not detect them.

\subsection{Purification}

Carbon nanotubes are usually contaminated with metal catalysts, amorphous carbon and graphitic nanoparticles and the presence of these impurities has hindered their
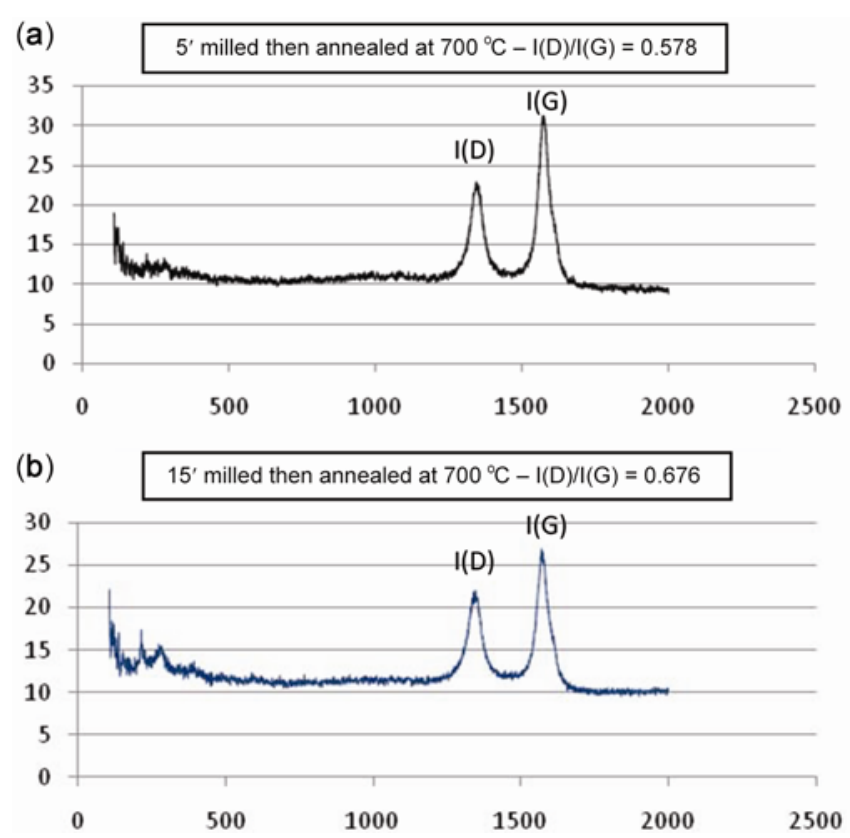

Figure 7. Raman spectra of CNTs synthesized using (a) 5-min and (b) 15-min milled powders.

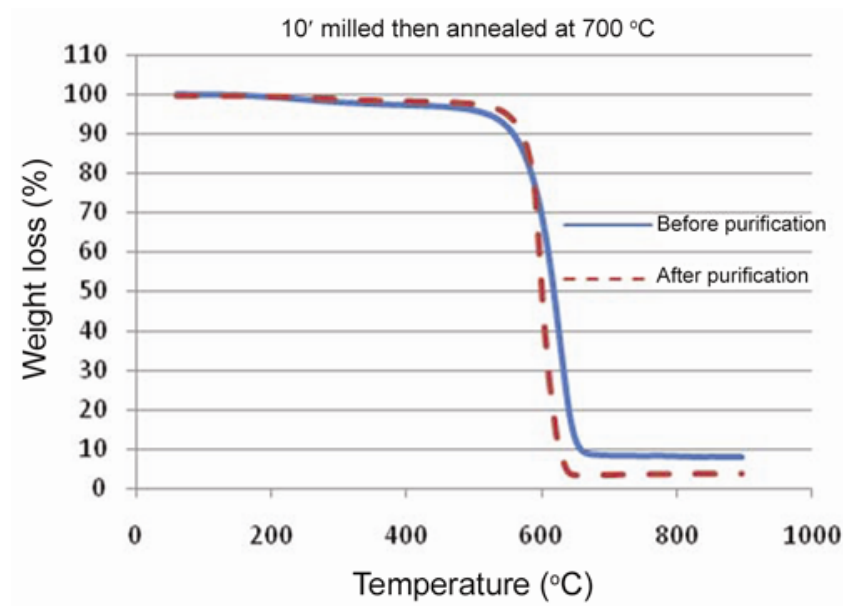

Figure 8. TGA curves of CNTs synthesized using $10 \mathrm{~min}$ milled powder before and after purification. application. A large number of purification methods have been reported, but refluxing nitric acid has probably been the treatment that has been employed most often, at least as the initial step in purification ( $\mathrm{Hu}$ et al 2003). The major function of nitric acid treatment is to remove metal catalysts, perhaps together with some of the amorphous carbon. Figure 8 shows the TGA analyses of the CNTs synthesized from 10-min milled powder and nitric acidtreated products. The weight loss curves directly reflect the occurrence of burning of carbon nanotubes. As it can be seen, the onset of burning is around $520^{\circ} \mathrm{C}$ for both the samples. However, in the TGA curve of the nitric acid-treated products, the residual is lower than the nonpurified sample. This amount is related to the amorphous carbon and iron catalyst, which were dissolved.

\section{Conclusions}

In the current research, the authors present a new method for fabrication $\mathrm{Fe}$ nanocatalysts for synthesizing carbon nanotubes. For this purpose, aluminum/iron oxide/graphite mixtures were milled. The results remarked as follows:

(I) Since the nanocamposite is attained after a short milling time $(15 \mathrm{~min})$, the process is claimed as an energysaving process.

(II) The produced nanocomposite included with iron nanoparticles in an alumina and ball-milled graphite.

(III) The produced nanocomposite used as a catalyst to synthesize carbon nanotubes via chemical vapour deposition successfully.

(IV) The CNTs were grown according to tip-growth mechanism.

\section{Acknowledgements}

The authors thank Dr S Veselov and Novosibirsk State Technical University for their support with various microscopy and XRD facilities. Valuable discussions with Prof Anatholy Bataev are gratefully acknowledged.

\section{References}

Ajayan P M 2004 Nature 427402

Alexiadisa V I and Verykiosa X E 2009 Mater. Chem. Phys. 117528

Bonadiman R, Lima M D, Andrade M J and Bergmann C P 2006 J. Mater. Sci. 417288

Cui H, Zhou O and Stoner B R 2000 J. Appl. Phys. 886072

Dai H 2002 Acc. Chem. Res. 351035

Ding J, Miao W F, McCormick P G and Street R 1995 Appl. Phys. Lett. 673804

Ding J, Liu B H, Dong Z L, Zhong Z Y, Lin J Y and White T 2004 Compos. B35 103

Ducati C, Alexandrou I, Chhowalla M, Amaratunga G A J and Robertson J 2002 J. Appl. Phys. 923299

Dupuis A C 2005 Prog. Mater. Sci. 50929 
Eskandarany M S E 2001 Mechanical alloying for fabrication of advanced engineering materials (New York: Noyes Publications/William Andrew Publishing) p. 37

Fecht H J 1995 NanoStruct. Mater. 633

$\mathrm{Hu} \mathrm{H}$, Zhao B, Itkis M E and Haddon R C 2003 J. Phys. Chem. B107 13838

Jianwei L, Xiaojun L, Amanda S, Toshiyuki O and Liming D 2005 Chem. Mater. 176599

Journet C, Maser W K, Bernier P, Loiseau A, de la Chapelle M L, Lefrant S, Deniard P, Lee R and Fischer J E 1997 Nature 388756

Juang Z Y, Chien I P, Lai J F, Lai T S and Tsai C H 2004 Diam. Relat. Mater. 131203

Laurent C, Flahaut E, Peigney A and Rousset A 1998 New J. Chem. 221229

Liu B H, Ding J, Dong Z L, Zhong Z Y, Lin J Y and White T 2006 Solid State Phenom. 111183

Luisetto I, Pepe F and Bemporad E 2008 J. Nanopart. Res. 1059

Magrez A, Seo J W, Smajda R, Mionić M and Forró L 2010 Mater. 34871

Maschmann M T, Amama P B, Goyal A, Iqbal Z, Gat R and Fisher T S 2006 Carbon 4410

Muñoz J, Cervantes J, Esparza R and Rosas G 2007 J. Nanopart. Res. 9945

Narkiewicz U, Podsiadły M, Jedrzejewski R and Pełech I 2010 Appl. Catal. A-Gen. 38427

Narkiewicz U, Podsiadły M, Arabczyk W, Wozniak M J and Kurzydlowski K J 2007 Mater. Sci. Eng. C27 1273
Nerushev O A, Dittmar S, Morjan R E, Rohmund F and Campbell E E B 2003 J. Appl. Phys. 934185

Parka J B, Choia G S, Choa Y S, Honga S Y, Kima D, Choib S Y, Leeb J H and Cho K I 2002 J. Cryst. Growth 244211

Paul S and Samdarshi S K 2011 New Carbon Mater 2685

Perez-Cabero M, Rodriguez-Ramos I and Guerrero-Ruız A 2003 J. Catal. 215305

Rümmeli M H, Kramberger C, Schäffel F, Borowiak-Palen E, Gemming T, Rellinghaus B, Jost O, Löffler M, Ayala P, Pichler T and Kalenczuk R J 2007 Phys. Status Solidi (B) 244 3911

Sharifi E M, Karimzadeh F and Enayati M H 2009 J. Alloys Compd. $\mathbf{4 8 2} 110$

Sheng Y, Yonghe L and Hoyi L 2002 Key Eng. Mater. 2179

Suryanarayana C 2001 Prog. Mater. Sci. 461

Takenaka S, Kobayashi S, Ogihara H and Otsuka K 2003 J. Catal. 21779

Tessonnier J P, Rosenthal D, Hansen T W, Hess1 C, Schuster M E, Blume R, Girgsdies F, Pfander N, Timpe O, Su D S and Schlogl R 2009 Carbon 471779

Thess A et al 1996 Science 273483

Xiaomei G, Jifa Q and Kenji S 2003 Scr. Mater. 481185

Yu Z, Chen D, Totdal B and Holmen A 2005 Catal. Today 100 261

Yunyu W, Zhiquan L, Bin L, Paul S H, Zhen Y, Li S, Eugene N B and Robert J N 2007 J. Appl. Phys. 101124310

Zhang C, Pisana S, Wirth C T, Parvez A, Ducati C, Hofmann S and Robertson J 2008 Diam. Relat. Mater. 171447 